\title{
A Specially Designed Pillow Can Decrease Developmental Plagiocephaly in Young Infants
}

\author{
Anna Öhman \\ Department of Paediatrics, University of Gothenburg, Gothenburg, Sweden \\ Email: anna.ohman@friskispraktiken.com
}

Received 17 March 2014; revised 25 April 2014; accepted 2 May 2014

Copyright (C) 2014 by author and Scientific Research Publishing Inc. This work is licensed under the Creative Commons Attribution International License (CC BY). http://creativecommons.org/licenses/by/4.0/ c) (i) Open Access

\begin{abstract}
Developmental plagiocephaly (DP) has been an increasing problem since the successful "back to sleep campaign". The referrals for DP have increased by more than $400 \%$ during the years 2004 to 2008. Many infants spend less time in the prone position nowadays and some of the risk factors for DP are: tummy time less than 3 times per day, torticollis and slow achievement of motor milestones. Improved information for the parents is needed but also other strategies to prevent DP. This study is a continuum of an earlier pilot study; the aim was to investigate the effect of a pillow, designed to reduce pressure on the infant head. Method: Infants aged zero to two months were included in the study. They were randomized to either intervention group or control group. Head shape was investigated on two occasions, on the second occasion motor development, mobility and muscle function of the neck were also investigated. The parents were asked about tummy time and sleep position. All infants were investigated by the same physical therapist, blinded to group belonging. Result: Fishers exact test showed that it was more common with decreased CVAI among infants in the intervention group ( $P$ 0.001). Paired $t$ test showed significant decrease in CVAI for the intervention group ( $P$ 0.002), but not for the control group (P 0.96). Conclusion: This study shows that a specially designed pillow can decrease DP in young infants.
\end{abstract}

\section{Keywords}

Developmental Plagiocephaly, Infant, Pillow, Motor Development, Tummy Time

\section{Introduction}

Developmental plagiocephaly (DP) is a condition in which the infant's skull is deformed as a result of prenatal 
or postnatal external moulding forces to the growing cranium [1] [2]. If an infant spends most of the time in supine with the head in the same position, this leads to DP [3]-[7]. The head growth is most rapid during the first six months of life, especially the first three months; hence the DP can develop very quickly in a newborn child [8]. There is a peak for DP at 4 months of age [5] [9]. Risk factors to develop plagiocephaly are: to be a firstborn child, male, twin, premature, tummy time $<3$ times per day when awake, torticollis and slow achievement of motor milestones [2]-[7] [10]-[14]. The incidence for DP is about 20\% [5] [15], also higher incidence rates are reported of up to 48\% [9]. The natural history of DP is likely to have existed for centuries although at a lower rate than at present [16]. The incidence of DP has increased since the back to sleep campaign [17] [18]. Between the years 2004 and 2008, the increase in referrals for DP was 407\% [19]. There is no doubt that infants ought to sleep on the back as the back to sleep campaign has resulted in a successful decrease in sudden infant death syndrome (SIDS) [20]. However, a negative side effect of the campaign is that some parents never put their infant in the prone position [21] [22], which increases the risk of DP and late motor development [23].

According to Lauritzen et al., there is a possibility that a soft pillow may decrease the risk of DP or reduce the asymmetry [24], but there is no evidence of the effect of pillows. In Sweden pillows are frequently used as they had previously been recommended for infants by the "National Board of Health and Welfare". New updated recommendations were presented in Stockholm at "the National Conference of Medicine" in December 2013, and the use of a pillow is no longer included in the recommendations. Although there is high usage of pillows in Sweden DP is still common; one study showed that $40 \%$ of the infants in a healthy control group had some level of DP at the age of two months, mostly of a lesser degree [23]. This indicates that an ordinary pillow isn't enough to prevent DP. It is unknown if an ordinary pillow can reduce the severity of DP to some extent. The use of pillows is questioned in many countries; some see it as a risk factor of SIDS [25]-[28]. According to two studies the use of a pillow does not increase the risk of SIDS as long as the infant is placed and stays in supine when using the pillow [29] [30]. However, if the infant sleeps in prone with a pillow this increases the risk of sudden infant death syndrome (SIDS) [30]. Pillows should not be used after an infant starts to turn over to a prone position. The Mimos pillow is a specially designed pillow that has been made to reduce pressure on the infant's head. This pillow was evaluated in a pilot study that indicated that using it could decrease DP [31]. However more infants had to be included in the study to confirm or disprove the result.

The aim with the current study was to investigate if the use of the Mimos pillow can decrease DP among young infants. The local ethical committee approved the study and the parents gave their informed consent.

\section{Method}

Nurses at the health care centres (all healthy infants attend these centres in Sweden) asked parents of infants aged zero to two months if they would give permission for their infant to participate in the study. The original plan was to include 200 infants in the study, but as a clear significance was already evolving with fewer infants the study was stopped earlier.

The infants were assessed on two occasions; the last assessment was scheduled to take place when the infants were three months of age. This age was chosen for ethical reasons; if any infant had or developed DP during the study there would still be time to use contra positioning to achieve a symmetrical head shape after the last assessment. The families who agreed to participate were randomized to one of two groups: intervention or control group. The parents were asked to pull a sealed envelope from a stack. The content of the envelope identified their group. Another person (with no other role in the study) opened the envelopes, the information about group belonging was sent to the parents after the first assessment. Both groups received written information about why tummy time is beneficial when the infant is awake. The intervention group received a Mimos pillow (Figure 1) and was asked to use it as much as possible; in the bed, the pram and whenever the infants spent much time in supine.

Both groups were assessed in the same way, all by the same investigator who was blinded to the group belonging.

On the first occasion the diagonals of the head were measured with a craniometer (Figure 2). The parents were asked about their infant's age, birth weight and length, and week of gestation. Information about the measurements of diagonals of the head was not revealed to the parents; the head shape was not commented on at all by the examiner. The parents were also asked not to reveal group belonging to the examiner before the second assessment was completely finished. 


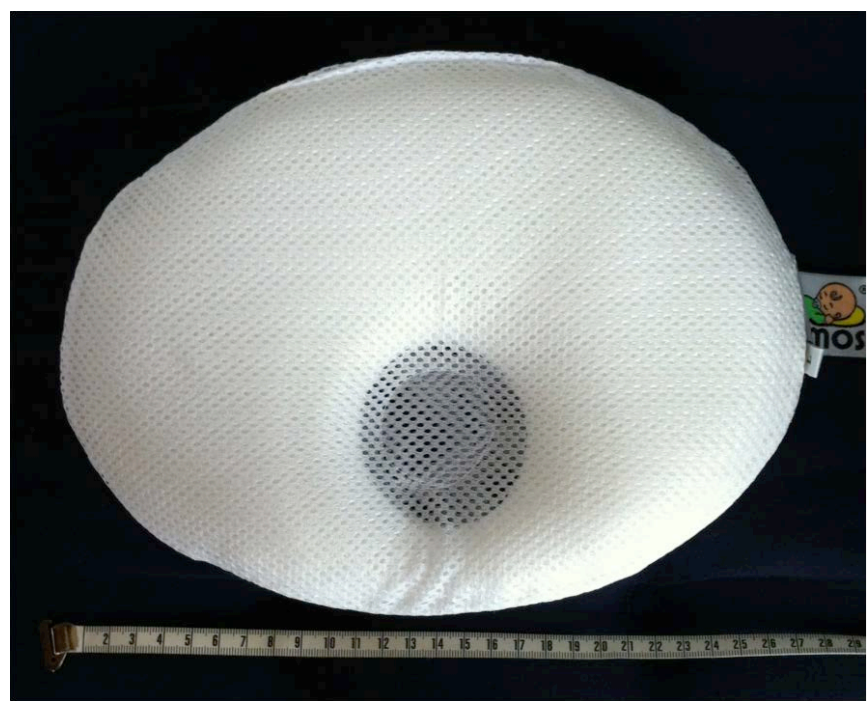

Figure 1. The Mimos pillow.

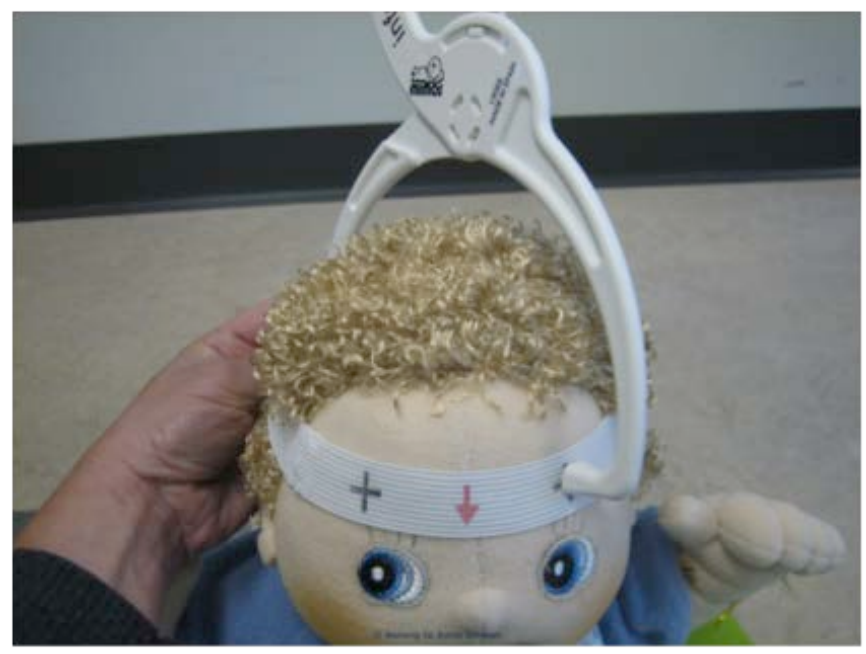

Figure 2. Measurement with the craniometer, a headband helps to find landmarks.

On the second/last assessment the diagonals of the head were measured again, the infant was also assessed for motor development with SOMP-I [32]. SOMP-I assesses motor function and motor performance, asymmetry between right and left sides were noted. Hence lack of head control, asymmetry of the head and a favoured side can be discovered.

Range of Motion (ROM) of the neck in lateral flexion and rotation was measured, muscle function in the lateral flexors of the neck and head tilt were examined [33] [34]. The parents were asked about the infants sleep position and amount of tummy time when awake. When the second i.e. last examination was completed the parents were asked about group belonging. They were also asked whether they had used a wedge or some other means to relieve pressure from the infant's head.

When analysing data the Cranial Vault Asymmetry Index (CVAI) was calculated. The index is calculated as the percentage difference of length in one quadrant versus the corresponding length in the other quadrant. Zero percent represent equal proportions, a CVAI $>3.5$ is considered significant plagiocephaly [35].

\section{Statistics}

Descriptive statistics were used for tummy time, sleep position, MFS and ROM. 
Fishers exact test was used to compare groups and decreased CVAI. Paired t test was used to examine changes between the first and last assessments in the two groups.

The significance level of P 0.05 was chosen.

\section{Result}

The parents of 84 infants responded positively to participation in this study, however the parents of three infants cancelled the last assessment. Group belonging was blinded until the end of the last assessment and the participants were entitled to leave the study without any explanation; there is no knowledge of which group these infants were randomized to. Eighty-one infants completed the study, 35 female and 46 male. Mean for birth weight was 3526 gram, mean birth length $50.1 \mathrm{~cm}$ and mean gestation week was 39.6. The mean age on the first assessment was 38.7 days. The mean age on the second i.e. last assessment was 94.4 days. The groups were similar (Table 1).

In the intervention group two children only used the pillow for short periods in the pram in the daytime, not at all indoors (day or night), these two infants were the only infants who were excluded from the analysis.

The remaining 79 infants were analysed; the distribution to the two groups were 44 infants in the intervention group and 35 infants in the control group. Six infants in the control group had been sleeping on the side; five of them had decreased CVAI on the last assessment. Two infants did not use the pillow in the daytime but used it during the night; they both had increased CVAI on the last assessment. One infant in the intervention group had slept a lot in the car seat (without the pillow) this infant had increased CVAI. The most common problem parents experienced during the study were that the infant sometimes glides off the pillow. Seven of the infants in the intervention group who had problems to stay on the pillow had increased CVAI.

A significant plagiocephaly i.e. CVAI $>3.5$ was found in $20 \%$ of the infants on the last assessment. Of these $64 \%$ had a low score in motor development i.e. at the assessment with SOMP-I, for all participants there were low scores for $34 \%$. Little tummy time i.e. 0 - 2 times a day were noted for $71 \%$ of the infants with CVAI $>3.5$ and for all participants $48 \%$ had had little tummy time. None of the infants had ROM $<90^{\circ}$ in rotation of the neck, but 23\% had a small difference of about $5^{\circ}$, all had full ROM in lateral flexion. An imbalance in the lateral flexors of the neck was found in $34 \%$ of the infants, half had a two score difference on the MFS and half had one score difference. For the infants with CVAI > 3.5, 50\% had a muscular imbalance. Little time in prone when awake was more common (75\%) for infants with a two score difference. Twenty-nine infants had low scores on the SOMP-I, 25 (93\%) of these infants had little tummy time when awake, 10 were female and 19 were male. Sixty-five percent of the infants slept in the supine position, $9 \%$ in the side position, $1 \%$ in the prone position and $25 \%$ in mixed positions (mostly a mix of supine and side positions). Fifty-three percent of the infants had a tendency or an obvious preferred side to rotate the head to when in a certain position according to the SOMP-I, this could be in prone, supine, or when held in sitting or standing. Of these with a favourite side $53 \%$ had a

Table 1. This is showing that there were no significant differences between the groups. There were slight differences with higher values in the intervention group for CVAI > 3.5, male, birth weight and length, favourite side and imbalance in muscle function in the lateral flexors of the neck.

\begin{tabular}{|c|c|c|}
\hline & $\begin{array}{l}\text { Intervention group } \\
\text { N } 44\end{array}$ & $\begin{array}{l}\text { Control group } \\
\text { N } 35\end{array}$ \\
\hline CVAI $<3.5$ at start of study & $32(73 \%)$ & $27(77 \%)$ \\
\hline CVAI > 3.5 at start of study & $12(27 \%)$ & $8(23 \%)$ \\
\hline Gender & $\begin{array}{l}19 \text { female (43\%) } \\
25 \text { male }(57 \%)\end{array}$ & $\begin{array}{c}17 \text { female (49\%) } \\
18 \text { male (51\%) }\end{array}$ \\
\hline Birth weight mean & 3576 gram & 3451 gram \\
\hline Birth length mean & $51.3 \mathrm{~cm}$ & $50.0 \mathrm{~cm}$ \\
\hline Gestation week & 39.9 & 39.2 \\
\hline Favorite side & $25(57 \%)$ & $18(51 \%)$ \\
\hline Imbalance in muscle function in the lateral flexors of the neck & $15(34 \%)$ & $11(31 \%)$ \\
\hline Low SOMP-I score & $15(34 \%)$ & $12(34 \%)$ \\
\hline Low amount of tummy time when awake, 0 - 2 times a day & $20(45 \%)$ & $18(51 \%)$ \\
\hline
\end{tabular}


muscular imbalance in the lateral flexors of the neck. Some degree of head tilt was seen in $19 \%$ of the participants, of these $87 \%$ had a muscular imbalance in the lateral flexors of the neck.

Fishers exact test showed that it was more common with decreased CVAI among infants in the intervention group (P 0.001). Paired t test showed significant decrease in CVAI for the intervention group (P 0.002), but not for the control group (P 0.96).

A CVAI of zero at the last assessment was found in $29 \%$ of the infants in the intervention group and $11 \%$ of the infants in the control group.

\section{Discussion}

This study shows that a specially designed pillow; the Mimos pillow can decrease the risk of DP in young infants. Other ways that are used to reduce pressure on the back of the infants head are to use a wedge and let the infant sleep on the side (half side/back) or letting the infant sleep in prone. However to sleep in prone is not recommended for young infants as this increases the risk of SIDS [20]. Also it is advisable to avoid side sleeping. The prevention and treatment of DP should not be allowed to increase the risk of SIDS. Safe ways to prevent and treat DP have to be found, investigated and communicated. Studies have shown that counter-positioning give improved head shape [15] [35]. However studies about conservative treatment are few and the study designs and methodology are moderate to poor [15]. In studies comparing helmet treatment with counter-positioning parents have been asked not to put their infant on the flat side of the head, but without being recommended to use a wedge. Without the use of a wedge this is not easy to accomplish, especially if the infants are used to sleep in supine with the head in a favorite position.

A limitation in rotation and/or a muscular imbalance in the neck could affect the head position, i.e. may promote a favored side of the head [7] [13]. However a minor decrease in rotation gives no limitation to rotate the head in both directions when the infant is placed in supine, a rotation of about $70^{\circ}$ enables the head to reach the mattress. The reference value for rotation of the neck in infants is mean $110^{\circ}$ [33]. All infants in the current study had at least $90^{\circ}$ of rotation of the neck. A muscular imbalance in the neck may have a greater effect on head position. Golden et al. found that $64 \%$ of infants with DP had muscular imbalance in the neck [13]. In the current study a muscular imbalance in the lateral flexors of the neck was found in $34 \%$ of the infants and was more common in the group with CVAI > 3.5. Head tilt was rather common and for most of these infants there were also a muscular imbalance, this may suggest that a mild torticollis in younger infants is fairly common. The incidence of suspected torticollis is similar with the incidence that Stellwagwen et al. found in their study.

In my clinical experience I have found that a muscular imbalance and/or mild torticollis can disappear if the infant is given a lot of tummy time early.

A significant plagiocephaly i.e. CVIA > 3.5 [35] was found in $20 \%$ on the last assessment. The reported incidence for DP varies between $20 \%$ - 48\% [5] [9] [15]. This discrepancy is probably due to the cohort being investigated and the criteria used; the milder asymmetries are not always included in studies. However, also a mild DP can concern the parents and later the individual as the infant gets older. In the current study only $20 \%$ of all participants had CVAI zero on the last assessment. In clinic parents can be worried also when the CVAI is as small as e.g. 2.0.

Early intervention is needed to prevent DP [4] [16] [24] [36]-[38]. The most important factor to stop DP is to vary the head position from the start when the infant is newborn [6] [10] [24] [36]. To have a lot of tummy time also seems to prevent DP [4] [10] [39]-[41]. Early detection and treatment of muscular imbalance in the infant neck may be preventative [13]. If starting "late" with tummy time the infant may resist and the parents may give up. By starting early with tummy time most infants will accept it.

It was slightly surprising to find that only $65 \%$ of the infants in the current study slept exclusively in supine, in an earlier study in the same city $>95 \%$ of the infants slept in supine [23]. This may reflect a new generation of parents. It seems that there is a need to improve parent-education about the importance of tummy time when the infants are awake and also that the safest position when sleeping is supine.

\section{Conclusion}

This study showed that there was a significant decrease in CVAI for the infants in the intervention group i.e. infants who had used the specially designed pillow. Imbalance in the lateral flexors of the neck was more common for infants with CVAI > 3.5. Information to parents on how to prevent developmental plagiocephaly needs to be 
repeated and improved. This study also indicates that prevention for SIDS may need to be intensified. Further investigation is needed to identify if the specially designed pillow is effective after the age of 3 months.

\section{References}

[1] Clarren, S.K. (1981) Plagiocephaly and Torticollis: Etiology, Natural History and Helm Treatment. Journal of Pediatrics, 98, 92-95. http://dx.doi.org/10.1016/S0022-3476(81)80549-5

[2] Littlefield, T.R., Kelly, K.M., Pomatto, J.K. and Beals, S.P. (2002) Multiple-Birth Infants at Higher Risk for Development of Deformational Plagiocephaly: II. Is One Twin at Greater Risk? Pediatrics, 109, 19-25.

http://dx.doi.org/10.1542/peds.109.1.19

[3] McKinney, C.M., Cunningham, M.L., Holt, V.L., Leroux, B. and Starr, J.R. (2009) Case-Control Study of Infant, Maternal and Perinatal Characteristics Associated with Deformational Plagiocephaly. Paediatric and Perinatal Epidemiology, 23, 332-345. http://dx.doi.org/10.1111/j.1365-3016.2009.01038.x

[4] Hutchison, B.L., Thompson, J.M. and Mitchell, E.A. (2003) Determinants of Nonsynostotic Plagiocephaly: A CaseControl Study. Pediatrics, 112, e316. http://dx.doi.org/10.1542/peds.112.4.e316

[5] Hutchison, B.L., Hutchison, L.A.D., Thompson, J.M.D. and Mitchell, E.A. (2004) Plagiocephaly and Brachycephaly in the First Two Years of Life: A Prospective Cohort Study. Pediatrics, 114, 970-980.

http://dx.doi.org/10.1542/peds.2003-0668-F

[6] Van Vlimmeren, L.A., van der Graaf, Y., Boere-Boonekamp, M.M., L’Hoir, M.P., Helders, P.J. and Engelbert, R.H.H. (2007) Risk Factors for Deformational Plagiocephaly at Birth and at Seven Weeks of Age: A Prospective Cohort Study. Pediatrics, 119, e408-e418. http://dx.doi.org/10.1542/peds.2006-2012

[7] Oh, A.K., Hoy, E.A. and Rogers, G.F. (2009) Predictors of Severity in Deformational Plagiocephaly. Journal of Craniofacial Surgery, 20, 685-689. http://dx.doi.org/10.1097/SCS.0b013e318193d6e5

[8] Brofin, D.R. (2001) Misshapen Heads in Babies: Position or Pathology? The Ochsner Journal, 3, 191-199.

[9] Robinson, S. and Proctor, M. (2009) Diagnosis and Management of Deformational Plagiocephaly. A Review. Journal of Neurosurgery, 3, 284-295.

[10] Peitsch, W.K., Keefer, C.H., LaBrie, R.A. and Mulliken, J.B. (2002) Incidence of Cranial Asymmetry in Healthy Newborns. Pediatrics, 110, e72. http://dx.doi.org/10.1542/peds.110.6.e72

[11] Joganic, J.L., Lynch, J.M., Littlefield, T.R. and Verrelli, B.C. (2009) Risk Factors Associated with Deformational Plagiocephaly. Pediatrics, 124, e1126-e1133. http://dx.doi.org/10.1542/peds.2008-2969

[12] Hutchison, B.L., Stewart, A.W. and Mitchell, E.A. (2009) Characteristics, Head Shape Measurements and Developmental Delay in 287 Consecutive Infants Attending a Plagiocephaly Clinic. Acta Pcediatrica, 98, 1494-1499.

http://dx.doi.org/10.1111/j.1651-2227.2009.01356.x

[13] Golden, K.A., Beals, S.P., Littlefield, T.R. and Pomatto, J.K. (1999) Sternocleidomastoid Imbalance versus Congenital Muscular Torticollis: Their Relationship to Positional Plagiocephaly. Cleft Palate-Craniofacial Journal, 36, $256-261$. http://dx.doi.org/10.1597/1545-1569(1999)036<0256:SIVCMT>2.3.CO;2

[14] Rogers, G.F., Oh, A.K. and Mulliken, J.B. (2009) The Role of Congenital Muscular Torticollis in the Development of Deformational Plagiocephaly. Plastic and Reconstructive Surgery, 123, 643-652. http://dx.doi.org/10.1097/PRS.0b013e318196b9be

[15] Bialocerkowski, A.E., Vladusic, S.L. and Wei, C. (2008) Prevalence, Risk Factors and Natural History of Positional Plagiocephaly: A Systematic Review. Developmental Medicine \& Child Neurology, 50, 577-586. http://dx.doi.org/10.1111/j.1469-8749.2008.03029.x

[16] Persing, J., James, H., Swanson, J., Kattwinkel, J. and American Academy of Pediatrics Committee on Practice and Ambulatory Medicine, Section on Plastic Surgery and Section on Neurological Surgery (2003) Prevention and Management of Positional Skull Deformities in Infants. Pediatrics, 112, 199-202. http://dx.doi.org/10.1542/peds.112.1.199

[17] Argenta, L.C., David, L.R., Wilson, J.A. and Bell, W.O. (1996) An Increase in Infant Cranial Deformity with Supine Sleeping Position. Journal of Craniofacial Surgery, 7, 5-11. http://dx.doi.org/10.1097/00001665-199601000-00005

[18] Kane, A.A., Mitchell, L.E., Craven, K.P. and Marsch, J.L. (1996) Observations on a Recent Increase in Plagiocephaly without Synostosis. Pediatrics, 97, 877-885.

[19] White, N., Warner, R.M., Noons, P., McAlister, E.M, Solanki, G., Nishikawa, H. and Dover, M.S. (2010) Changing Referral Patterns to a Designated Craniofacial Centre over a Four-Year Period. Journal of Plastic, Reconstructive \& Aesthetic Surgery, 63, 921-925. http://dx.doi.org/10.1016/j.bjps.2009.05.007

[20] Wennergren, G. (2004) Prevention of Sudden Infant Death Syndrome. Pediatric Pulmonology, 26, 110-111. http://dx.doi.org/10.1002/ppul.70072 
[21] Majnemer, A. and Barr, R.G. (2005) Influence of Supine Sleep Positioning on Early Motor Milestones Acquisition. Developmental Medicine \& Child Neurology, 47, 370-376.

[22] Mildered, J., Beard, K., Dallwitz, Z. and Unwin, J. (1995) Play Position Is Influenced by Knowledge of SIDS Sleep Position Recommendations. Journal of Paediatrics and Child Health, 31, 499-502. http://dx.doi.org/10.1111/j.1440-1754.1995.tb00871.x

[23] Öhman, A., Nilsson, S., Lagerkvist, A.L. and Beckung, E. (2009) Are Infants with Torticollis at Risk for a Delay in Early Motor Milestones Compared with a Control Group of Healthy Infants? Developmental Medicine \& Child Neurology, 51, 545-550. http://dx.doi.org/10.1111/j.1469-8749.2008.03195.x

[24] Lauritzen, C. and Tarnow, P. (1999) Assymetric Skull? Early Correct Diagnosis Is a Must! Positional Skull Deformities Can Be Avoided. Lakartidningen, 96, 1447-1453.

[25] Hauck, F.R., Herman, S.M., Donovan, M., Ivasu, S., Moore, C.M., Donoghue, E., Kirschner, R.H. and Willinger, M. (2003) Sleep Environment and the Risk of Sudden Infant Death Syndrome in an Urban Population: The Chicago Infant Mortality Study. Pediatrics, 111, 1207-1214.

[26] van Sleuwen, B.E., L’Hoir, M.P., Engelberts, A.C., Westers, P. and Schulpen, T.W. (2003) Infant Care Practise Related to Cot Death in Turkish and Moroccan Families in the Netherlands. Archives of Disease in Childhood, 88, 784788. http://dx.doi.org/10.1136/adc.88.9.784

[27] Scheers, N.J., Dayton, C.M. and Kemp, J.S. (1998) Sudden Infant Death with External Airways Covered Case-Comparision Study of 206 Deaths in the Untied States. Archives of Pediatrics and Adolescent Medicine, 152, 540-547. http://dx.doi.org/10.1001/archpedi.152.6.540

[28] Carpenter, R.G. and Shaddick, C.W. (1965) Role of Infection, Suffocation and Bottle-Feeding in Cot Death. Ananalysis of Some Factors in the Histories of 110 Cases and Their Controls. British Journal of Preventive and Social Medicine, 19, 1-7.

[29] McGarvey, C., McDonnell, M., Chong, A., O’Regan, M. and Matthews, T. (2003) Factors Relating to the Infant’s Last Sleep Environment in Sudden Infant Death Syndrome in the Republic of Ireland. Archives of Disease in Childhood, 88, 1058-1064.

[30] Thompson, J.M., Thach, B.T., Becroft, D.M. and Mitchell, E.A. (2006) New Zealand Cot Death Study Group. Sudden Infant Death Syndrome: Risk Factors for Infants Found Face Down Differ from Other SIDS Cases. The Journal of Pediatrics, 149, 630-633. http://dx.doi.org/10.1016/j.jpeds.2006.07.041

[31] Öhman, A. (2103) A Specially Designed Pillow May Be Used as Treatment for Young Infants with Developmental Plagiocephaly. Health, 5, 2064-2067.

[32] Persson, K. and Strömberg, B. (1995) Structured Observation of Motor Performance (SOMP-I) Applied to Neonatally Healthy Fullterm Infants at the Ages of 0 - 10 Months. Early Human Development, 40, 127-143. http://dx.doi.org/10.1016/0378-3782(94)01598-J

[33] Öhman, A. and Beckung, E. (2008) Reference Values for Range of Motion and Muscle Function in the Neck in Infants. Pediatric Physical Therapy, 20, 53-58. http://dx.doi.org/10.1097/PEP.0b013e31815ebb27

[34] Öhman, A., Nilsson, S. and Beckung, E. (2009) Validity and Reliability of the Muscle Function Scale, Aimed to Assess the Lateral Flexors of the Neck in Infants. Physiotherapy Theory and Practice, 25, 129-137. http://dx.doi.org/10.1080/09593980802686904

[35] Loveday, B.P. and de Chalain, T.B. (2001) Active Counterpositioning or Orthotic Device to Treat Positional Plagiocephaly? Journal of Craniofacial Surgery, 12, 308-313. http://dx.doi.org/10.1097/00001665-200107000-00003

[36] Jonsell, R. (1999) Infants Should Sleep in Supine Position. The Risk of Skull Deformities Can Be Prevented. Läkartidningen, 96, 1404-1405.

[37] Cavalier, A., Picot, M.C., Artiaga, C., Mazurier, E., Amilhau, M.O., Froye, E., Captier, G. and Picaud, J.C. (2011) Prevention of Deformational Plagiocephaly in Neonates. Early Human Development, 87, 537-543. http://dx.doi.org/10.1016/j.earlhumdev.2011.04.007

[38] Knudsen, B., Christensen, K., Baagøe, S., Hoppe, P., Juhl, C., Buus, L. and Jakobsen, T.L. (2011) Positional Plagiocephaly in Infants Can Be Prevented. Ugeskr for Laeger, 173, 644-648.

[39] American Academy of Pediatrics Task Force on Sudden Infant Death Syndrome (2005) The Changing Concept of Sudden Infant Death Syndrome: Diagnostic Coding Shifts, Controversies Regarding the Sleeping Environment, and New Variables to Consider in Reducing Risk. Pediatrics, 116, 1245-1255. http://dx.doi.org/10.1542/peds.2005-1499

[40] Nield, L.S., Brunner, M.D. and Kamat, D. (2007) The Infant with a Misshapen Head. Pediatrics, 46, 292-298.

[41] Robertson, R. (2011) Supine Infant Positioning-Yes, but There’s More to It. Journal of Family Practice, 60, 605-608. 